\title{
PRÉ-TESTE DE UM QUESTIONÁRIO PARA ESTUDO DO REGISTRO DE DADOS DE BUSCA POR INFORMAÇÃO TECNOLÓGICA
}

Eduardo Romeiro Filho (romeiro@dep.ufmg.br) - Universidade Federal de Minas Gerais, UFMG.

Guilherme Leal Fernandes (1985.guilherme@gmail.com) - Universidade Federal de Minas Gerais, UFMG.

\section{RESUMO}

Este estudo visa aperfeiçoar um questionário sobre a prática de registro de dados busca por informação tecnológica por profissionais da área de inovação tecnológica. A metodologia consistiu em um estudo piloto baseado no pré-teste do questionário com três etapas: 1) a aplicação do questionário individualmente para uma amostra de 11 respondentes da população alvo; 2) análise das respostas e realização de uma entrevista com cada respondente a fim de se obterem subsídios para aperfeiçoar o questionário; 3) analisar as anotações das entrevistas e efetuar ajustes e melhorias no questionário evidenciados na análise. Obteve-se um questionário testado e aperfeiçoado, além do desenvolvimento de uma metodologia aprimorada para o préteste.

Palavras-chave: questionário; pré-teste; patentes; buscas, inovação. 


\section{INTRODUÇÃO}

O levantamento do “Estado da Técnica”, etapa essencial aos processos de inovação, inclui uma pesquisa em bases de dados de patentes, tarefa que não é trivial. A busca é um procedimento de consulta em que termos de busca, por exemplo palavras-chave, são submetidos em campos de busca em bases de dados de patentes.

A consulta realizada retorna como resultado documentos de patentes que satisfazem aos critérios de busca delimitados pelos termos pesquisados (WORLD INTELLECTUAL PROPERTY ORGANIZATION-WIPO, 2015). Muitos profissionais realizam rotineiramente tais buscas para recuperar informações tecnológicas e de aspectos legais e comerciais das tecnologias em escritórios de propriedade intelectual (PI), indústrias, núcleos de inovação tecnológica (NITs), instituições de pesquisa e outros.

Informação tecnológica representa o conhecimento sobre tecnologias de fabricação, de projeto e de gestão, para a melhoria contínua da qualidade e a inovação no setor produtivo (PARMAGNANI, 2004) e pode ser utilizada, por exemplo, para análise de patenteabilidade, identificar tecnologias emergentes, tendências de mercado e previsão de novos produtos (WIPO, 2015), sendo essencial para a inovação.

Durante a realização de buscas por patentes, uma série de dados de consulta da busca como os termos, os operadores e campos de buscas, bem como as bases de dados consultadas e informações sobre os resultados de busca podem ser registrados.

Atualmente há poucas publicações sobre o registro dos dados de consulta da busca, poucas pesquisas na literatura apresentam informações ou discussões acerca dos motivos do registro ou da forma como é realizado, tampouco da utilização dos dados de consulta da busca quando são registrados. Ressalta-se que é raro acessar o comportamento de busca de profissionais que realizam buscas de patentes, pois tais profissionais geralmente não têm tempo nem interesse em permitir que os pesquisadores os observem ou os entrevistem, uma vez que a divulgação de suas estratégias costuma ser um assunto delicado e sigiloso.

Tais dificuldades, conforme discute Jürgens, Hansen e Womser-Hacker (2012), permitem entender, em parte, a escassez de estudos e publicações sobre o assunto. No domínio de 
patentes, os registros de consultas de busca (ou query logs, como são denominados em estudos na área publicados na língua inglesa) são difíceis de serem acessados.

No setor privado, de acordo com Tannebaum (2015), as empresas e pesquisadores hesitam em tornar seus registros de consulta disponíveis, pois temem revelar suas atividades de pesquisa e desenvolvimento. Especificamente no Brasil, não foram observados estudos contendo informação sobre a ocorrência ou a finalidade da prática do registro de dados de consulta das buscas. Para suprir essa deficiência de informações, com a qual também corrobora a literatura, propõe-se uma consulta aos profissionais da área de inovação tecnológica para investigar a prática do registro.

O resultado futuro tem potencial para aumentar a compreensão sobre os processos de busca por informação tecnológica, pois um questionário será utilizado nesta pesquisa exploratória e descritiva como meio de se conhecer se há registro, os motivos do registro, a forma como é realizado e a utilização dos dados registrados, possibilitando a geração de soluções que tornarão os processos envolvendo busca de informação tecnológica mais transparentes, céleres, organizados e confiáveis, além de apontar formas de economizar o tempo dos profissionais e auxiliá-los em suas tarefas de busca, beneficiando-se diretamente as instituições em que trabalham.

Como resultado parcial há um questionário desenvolvido para obter tais informações dos profissionais da área de inovação tecnológica que precisa passar por avaliação (pré-teste) para verificar sua adequação para obtenção das informações desejadas e aperfeiçoá-lo. Ao final do pré-teste será produzido um questionário aperfeiçoado e apto a ser utilizado como um instrumento de coleta de dados capaz de satisfazer aos objetivos da pesquisa principal sobre o registro de dados de consulta da busca por patentes, além de ser uma possibilidade de instrumento de coleta a ser reaproveitado e considerado em pesquisas posteriores dentro do mesmo tema.

Observando uma lacuna importante no desenvolvimento de ferramentas de pesquisa voltadas à inovação (neste caso especificamente a busca por informação tecnológica) este artigo apresenta a avaliação do questionário desenvolvido. Esta avaliação será por meio de um estudo piloto com o pré-teste do questionário. Se pretende: (1) aplicar o questionário a uma amostra da população alvo e posteriormente entrevistá-los para identificar possibilidades de melhoria no 
questionário; (2) analisar as respostas e entrevistas; (3) efetuar ajustes no questionário eventualmente evidenciados.

\section{REVISÃO DA LITERATURA}

\subsection{O Estudo piloto}

O estudo piloto é um teste em escala reduzida dos procedimentos e métodos propostos de pesquisa (MACKEY; GASS, 2005). Inclui a realização dos procedimentos previstos na metodologia para aperfeiçoar os instrumentos na etapa anterior à investigação em si. Quando a metodologia de pesquisa inclui a aplicação de questionário, o estudo piloto implicará em seu pré-teste numa amostra do grupo final da pesquisa para corrigir eventuais inadequações desapercebidas pelos pesquisadores e considerar a dinâmica da aplicação do questionário (MANZATO; SANTOS, 2012). Verifica-se se o instrumento mede o que se propõe a medir (CANHOTA, 2008).

\subsection{A Amostra do pré-teste}

Os respondentes escolhidos devem ser típicos em relação à população alvo da pesquisa principal e dispostos a dedicar maior tempo para responder ao questionário e serem entrevistados sobre dificuldades e limitações que encontraram no ato de responderem ao questionário (GIL, 1999).

A amostra pode ser selecionada por conveniência ou acessibilidade que, segundo Beuren (2004), o pesquisador inclui elementos na amostra não-probabilística pela facilidade de acesso, disponibilidade, por questões financeiras e de tempo.

Aaker, Kumar e Day (1995) apresentam que a amostragem por conveniência emprega-se em pré-testes de questionários porque o objetivo é simplesmente testar o instrumento e não produzir afirmações ou generalizações sobre a população alvo, o que demandaria maior rigor estatístico.

Sobre o tamanho da amostra do pré-teste, não precisa ser grande em relação à população alvo. Concordam entre si Canhota (2008), Fonseca et al. (2008) e Gil (1999) que 10 a 20 respondentes são suficientes para o pré-teste. 


\subsection{Coleta de dados dos respondentes}

Na metodologia proposta por Gil (1999), após o preenchimento do questionário, os respondentes são entrevistados. Manzini $(1990,2003)$ mencionam que a modalidade de entrevista semiestruturada orienta-se por um tema e utiliza roteiro para organizar a entrevista e coletar informações básicas contendo perguntas principais que são complementadas na circunstância da entrevista de forma flexível e dinâmica. Diferentemente da entrevista estruturada com respostas restritas à padronização de alternativas ou uma condução rigorosa da entrevista delimitada por questões previamente definidas.

Reforçam, Marconi e Lakatos (2010), a necessidade de espaços no questionário aplicado no pré-teste para que o respondente expresse-se sobre suas dificuldades de entendimento das questões e sua percepção quanto à ocorrência de embaraços, questões polêmicas, delicadas ou pessoais durante o preenchimento do questionário.

\subsection{Análise dos resultados do pré-teste}

Goode e Hatt (1972) afirmam que a análise dos resultados do pré-teste permitem que se conheçam as limitações do instrumento. Durante a análise observa-se: presença de questões difíceis, ambíguas e mal formuladas, a proporção de recusas de respostas e comentários feitos pelos respondentes sobre determinadas questões. As observações permitirão identificar as oportunidades de melhorias para o questionário e as ações necessárias para implementá-las.

\section{METODOLOGIA}

A metodologia delineada se originou de algumas escolhas e definições de procedimentos para Composição criteriosa da amostra; Aplicação do questionário e entrevista; Análise das respostas do questionário e das entrevistas; Ajustes no questionário. A figura 1 apresenta um diagrama que resume as etapas metodológicas que foram adotadas no pré-teste.

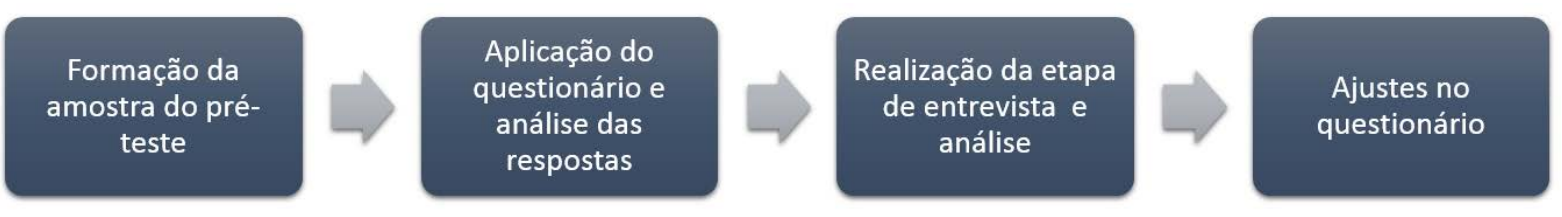

FIGURA 1 - Etapas principais da metodologia. Fonte: Elaborado pelo autor 


\subsection{Amostra do pré-teste}

A formação da amostra do pré-teste teve como critério a presença de respondentes que representassem pluralidade de instituições que realizam a busca por informação tecnológica incluindo respondentes com experiência em busca em NITs, universidades, indústrias e escritórios de PI, de modo a existir correspondência entre as características da amostra e da população-alvo, conforme sugerem Canhota (2008), Fonseca et al. (2008) e Gil (1999).

Definiu-se uma amostra formada por 11 respondentes (consonante com a literatura). O segundo critério foi a conveniência, o pesquisador tirou proveito da acessibilidade e boa relação com membros da população alvo para pedir-lhes que participassem do pré-teste, imaginando que o índice de recusa seria baixo e a existência de boa vontade em dedicarem tempo para responder ao questionário e, ainda, realizar entrevista. Esta escolha visa contornar em parte a dificuldade de recrutar respondentes dispostos para colaborar duplamente respondendo ao questionário e participando da entrevista, como evidencia Gil (1999).

\subsection{Aplicação do questionário e análise das respostas}

No questionário incluiu-se um campo aberto em cada questão para capturar manifestações textuais dos respondentes sobre eventuais dificuldades encontradas, de acordo com Marconi e Lakatos (2010). Após a aplicação do questionário as respostas e manifestações dos respondentes foram abordadas nas entrevistas. A análise das respostas dos questionários forneceu elementos que foram retomados, discutidos e aprofundados com os respondentes no momento da entrevista em que também abordou-se complementarmente um roteiro de perguntas:

1. Perguntar a razão de questões não respondidas, se for o caso;

2. Perguntar se percebeu alguma questão ambígua;

3. Perguntar algum constrangimento, inconveniente ou desconforto em responder alguma questão;

4. Perguntar se o respondente deseja expressar-se livremente sobre questionário.

\subsection{Análise}

As entrevistas foram anotadas e analisadas conforme os elementos norteadores evidenciados na literatura e discutidos por Gil (1999) e Goode e Hatt (1972) para identificar os elementos do 
questionário que eventualmente originam falta de clareza, ambiguidade e pontos falhos e corrigi-los.

\section{Resultados e Discussões}

Reuniu-se as manifestações da entrevista, em alguns casos emergiram sugestões, contribuições, inclusive ideias de aprimoramentos na abordagem do conteúdo no instrumento, fato que pode estar associado ao alto nível de formação dos respondentes e suas experiências significativas na atividade de busca por informação tecnológica. No quadro 1 apresentamos tais apontamentos para cada questão (coluna 4). A coluna Id. Identifica cada respondente.

\begin{tabular}{|c|c|c|c|c|c|}
\hline Id. & Instituição & $\begin{array}{l}\text { Área de } \\
\text { Formação }\end{array}$ & $\begin{array}{l}\text { Questão } \\
\text { Citada }\end{array}$ & & Apontamentos do respondente \\
\hline \multirow{3}{*}{ A } & \multirow{3}{*}{$\begin{array}{l}\text { NIT de Universidade } \\
\text { Pública }\end{array}$} & \multirow[t]{3}{*}{ Biotecnologia } & 3 & 1 & $\begin{array}{l}\text { Sugeriu remover ou deixar como opcional } \\
\text { a pergunta da idade do respondente. }\end{array}$ \\
\hline & & & 28 & 2 & $\begin{array}{l}\text { Não há como manifestar predominância ou } \\
\text { alternância ou ocorrência mútua dos } \\
\text { comportamentos apresentados nas } \\
\text { alternativas. }\end{array}$ \\
\hline & & & 43 e 44 & 3 & $\begin{array}{l}\text { Relatou esquecimento de dados de } \\
\text { registro, mas não esquece mais porque } \\
\text { registra os dados antes de submetê-los aos } \\
\text { campos das bases de dados. Sugeriu } \\
\text { alternativas na questão que permitissem } \\
\text { considerar sua situação. }\end{array}$ \\
\hline $\mathrm{B}$ & $\begin{array}{c}\text { Instituição de } \\
\text { Pesquisa Público }\end{array}$ & Biotecnologia & 3 & 4 & $\begin{array}{l}\text { Questionou a necessidade da pergunta da } \\
\text { idade do respondente. }\end{array}$ \\
\hline $\mathrm{C}$ & $\begin{array}{l}\text { Instituição federal de } \\
\text { educação tecnológica }\end{array}$ & Engenharia & 7,8 & 5 & $\begin{array}{l}\text { Criticou o limite mínimo de caracteres } \\
\text { para resposta que desconsiderou sua } \\
\text { resposta sobre a formação. }\end{array}$ \\
\hline $\mathrm{D}$ & $\begin{array}{l}\text { NIT de Universidade } \\
\text { Pública }\end{array}$ & Biotecnologia & - & - & - \\
\hline $\mathrm{E}$ & $\begin{array}{l}\text { Indústria } \\
\text { Farmacêutica }\end{array}$ & Farmácia & $\begin{array}{c}16,17 \mathrm{e} \\
18\end{array}$ & 6 & $\begin{array}{l}\text { Apontou falta de clareza sobre o tempo } \\
\text { gasto nas tarefas de busca, criticou a falta } \\
\text { de definição das etapas que formam a } \\
\text { busca porque gera dúvidas para estimar o } \\
\text { tempo gasto na busca. }\end{array}$ \\
\hline \multirow[b]{2}{*}{$\mathrm{F}$} & \multirow[b]{2}{*}{$\begin{array}{l}\text { NIT de Universidade } \\
\text { Pública }\end{array}$} & \multirow[t]{2}{*}{ Biotecnologia } & $\begin{array}{l}16,17 \mathrm{e} \\
18\end{array}$ & 7 & $\begin{array}{l}\text { Relatou que precisou ler muitas vezes para } \\
\text { entender. }\end{array}$ \\
\hline & & & $\begin{array}{c}6,7,8, \mathrm{e} \\
9\end{array}$ & & $\begin{array}{l}\text { Manifestou que } 4 \text { questões para obter a } \\
\text { formação do respondente é excessivo, } \\
\text { bastaria uma questão. }\end{array}$ \\
\hline G & $\begin{array}{l}\text { NIT de Universidade } \\
\text { Pública }\end{array}$ & Química & $\begin{array}{c}16,17 \mathrm{e} \\
18\end{array}$ & 8 & $\begin{array}{l}\text { Sugeriu deixar claro que a estimativa se } \\
\text { trata de um tempo médio baseado na } \\
\text { experiência do respondente. }\end{array}$ \\
\hline $\mathrm{H}$ & $\begin{array}{l}\text { NIT de Universidade } \\
\text { Pública }\end{array}$ & Direito & 3 & 9 & $\begin{array}{l}\text { Sugeriu remover a pergunta da idade do } \\
\text { respondente. }\end{array}$ \\
\hline I & $\begin{array}{l}\text { NIT de Universidade } \\
\text { Pública }\end{array}$ & Engenharia & 21 & 10 & $\begin{array}{l}\text { Manifestou que gostaria de indicar } \\
\text { justificativas para não registrar e se } \\
\text { percebe algum benefício em registrar, } \\
\text { mesmo não registrando. }\end{array}$ \\
\hline
\end{tabular}




\begin{tabular}{|c|c|c|c|c|c|}
\hline & & & 58 & 11 & $\begin{array}{l}\text { Criticou o limite numérico para resposta da } \\
\text { questão que não considerou sua resposta. }\end{array}$ \\
\hline $\mathrm{J}$ & Escritório de patentes & Direito & - & - & - \\
\hline $\mathrm{K}$ & Escritório de patentes & Engenharia & - & - & - \\
\hline
\end{tabular}

QUADRO 1 - Apontamentos dos respondentes consolidados na entrevista. Fonte: Elaborado pelo autor

Foram registrados também apontamentos gerais que são aplicáveis em várias questões:

I) Os respondentes $\mathrm{B}, \mathrm{F}$ e $\mathrm{H}$ apontaram o tamanho do questionário como excessivamente grande, tanto em número de questões como enunciados extensos

II) Os respondentes $\mathrm{H}$ e I sugeriram incluir o verbo utilizar no passado (utilizou ou utilizaram) para contemplar a situação dos respondentes que já exerceram atividades de busca, mas que atualmente não exercem mais.

Como solução dos apontamentos I e II efetuou-se:

a) Remoção da questão 3 sobre a idade, sem prejuízos para os aspectos essenciais medidos no questionário;

b) Substituição das questões 6, 7, 8, e 9 (sobre a formação) por somente uma questão aberta, sem prejuízos para obtenção da informação sobre formação.

c) Adequação dos tempos verbais (conforme apontamento II);

d) Revisão geral do questionário, reescrevendo trechos de forma mais objetiva e reduzida.

A execução das medidas (a), (b) e (d) reduziram o número de palavras em 20\% e o número de questões da seção 1 do questionário de 21 para 16. Os apontamentos do quadro 1 também foram contemplados por meio de intervenções apresentadas no quadro 2 pela comparação entre a redação das questões antes e após a intervenção, relacionando-as com o aspecto aperfeiçoado na intervenção.

\begin{tabular}{|l|l|l|l|}
\hline $\begin{array}{l}\text { Questã } \\
\text { o }\end{array}$ & \multicolumn{1}{|c|}{ Redação Original } & \multicolumn{1}{|c|}{ Redação Aperfeiçoada } & Aperfeiçoamento pretendido \\
\hline 6 & $\begin{array}{l}\text { Qual seu nível de escolaridade? } \\
\text { () Ensino médio, () Graduação } \\
\text { incompleta, () Graduação } \\
\text { completa, () Pós-graduação } \\
\text { incompleta, () Pós-graduação } \\
\text { completa. }\end{array}$ & $\begin{array}{l}\text { As questões 6, 7, 8 e 9 foram removidas } \\
\text { e substituídas pela seguinte questão: }\end{array}$ & $\begin{array}{l}\text { Clareza, redução do número de } \\
\text { questões e do tamanho das } \\
\text { questões. }\end{array}$ \\
\hline 7 & $\begin{array}{l}\text { Caso possua graduação } \\
\text { completa ou esteja cursando um } \\
\text { curso de graduação, indique o } \\
\text { curso: }\end{array}$ & $\begin{array}{l}\text { Indique os cursos de graduação e pós- } \\
\text { graduação concluídos por você: }\end{array}$ & \\
\hline
\end{tabular}




\begin{tabular}{|c|c|c|c|}
\hline 8 & $\begin{array}{l}\text { Possui pós-graduação? () Sim, } \\
\text { doutorado ou superior, } \\
\text { completo;()Sim, doutorado ou } \\
\text { superior, incompleto;()Sim, } \\
\text { mestrado, completo;()Sim, } \\
\text { mestrado, incompleto;()Sim, } \\
\text { especialização e outros, } \\
\text { completo;()Sim, especialização } \\
\text { e outros, incompleto;()Não } \\
\text { possuo pós-graduação. }\end{array}$ & & \\
\hline 9 & $\begin{array}{l}\text { Caso possua pós-graduação } \\
\text { completa ou esteja cursando um } \\
\text { curso de pós-graduação, indique } \\
\text { o curso e a área do } \\
\text { conhecimento relacionada: }\end{array}$ & & \\
\hline 16 & $\begin{array}{l}\text { PERGUNTA A: Quanto tempo } \\
\text { aproximadamente você gasta } \\
\text { em cada demanda individual de } \\
\text { pesquisa de busca de patentes } \\
\text { em um mesmo campo técnico } \\
\text { realizada em bases de dados de } \\
\text { patentes na internet? } \\
\text { (A medida de tempo utilizada } \\
\text { deve ser em horas) }\end{array}$ & $\begin{array}{l}\text { PERGUNTA A: Considerando sua } \\
\text { experiência, qual o tempo médio gasto } \\
\text { em cada demanda individual de busca, } \\
\text { incluindo leitura e análise de } \\
\text { documentos, pesquisa nas bases de } \\
\text { dados e até a conclusão da busca? } \\
\text { (A medida de tempo utilizada deve ser } \\
\text { em horas) }\end{array}$ & $\begin{array}{l}\text { Ressaltar que a estimativa de } \\
\text { tempo solicitada se trata de um } \\
\text { tempo médio baseado na } \\
\text { experiência do respondente. } \\
\text { Orientar o respondente pela } \\
\text { inclusão de uma definição sobre } \\
\text { as etapas que formam a busca, } \\
\text { para compreensão mais precisa } \\
\text { do termo “busca” utilizado na } \\
\text { questão. }\end{array}$ \\
\hline 17 & $\begin{array}{l}\text { Aproximadamente quanto do } \\
\text { tempo gasto informado na } \\
\text { pergunta anterior (PERGUNTA } \\
\text { A), é utilizado na leitura, } \\
\text { compreensão e análise de } \\
\text { relevância de documentos } \\
\text { encontrados na busca? (A } \\
\text { medida de tempo utilizada deve } \\
\text { ser em horas) }\end{array}$ & $\begin{array}{l}\text { Em média, quanto do tempo gasto } \\
\text { informado na pergunta anterior } \\
\text { (PERGUNTA A), é utilizado na leitura, } \\
\text { compreensão e análise de relevância de } \\
\text { documentos encontrados na busca? (A } \\
\text { medida de tempo utilizada deve ser em } \\
\text { horas) }\end{array}$ & \multirow{2}{*}{$\begin{array}{l}\text { Evidenciar que a estimativa de } \\
\text { tempo solicitada na questão se } \\
\text { trata de um tempo médio } \\
\text { baseado na experiência do } \\
\text { respondente. }\end{array}$} \\
\hline 18 & $\begin{array}{l}\text { Aproximadamente quanto do } \\
\text { tempo gasto, informado na } \\
\text { PERGUNTA A, é utilizado na } \\
\text { obtenção e reformulação de } \\
\text { consultas editando-as e } \\
\text { submetendo-as aos campos de } \\
\text { busca nas bases de dados de } \\
\text { patentes na internet? (A medida } \\
\text { de tempo utilizada deve ser em } \\
\text { horas) }\end{array}$ & $\begin{array}{l}\text { Em média, quanto do tempo gasto, } \\
\text { informado na PERGUNTA A, é } \\
\text { utilizado na obtenção e reformulação de } \\
\text { consultas editando-as e submetendo-as } \\
\text { aos campos de busca nas bases de dados } \\
\text { de patentes na internet? (A medida de } \\
\text { tempo utilizada deve ser em horas) }\end{array}$ & \\
\hline 21 & $\begin{array}{l}\text { Os dados de consulta de busca } \\
\text { são aqueles que você utiliza ou } \\
\text { obtém na busca, por exemplo, } \\
\text { códigos de classificação } \\
\text { IPCs/CPCs/outros, Palavras - } \\
\text { chave, campos de busca, } \\
\text { número de resultados } \\
\text { retornados na busca dentre } \\
\text { outros dados. Você registra } \\
\text { algum dos dados de consulta de } \\
\text { busca pesquisados em bases de } \\
\text { dados de patente na internet em } \\
\text { algum formulário ou } \\
\text { documento? () Sim; () Nunca } \\
\text { registro }\end{array}$ & $\begin{array}{l}\text { Os dados de consulta de busca são } \\
\text { aqueles que você utiliza ou obtém na } \\
\text { busca, por exemplo, códigos de } \\
\text { classificação IPCs/CPCs/outros, } \\
\text { Palavras-chave, campos de busca, } \\
\text { número de resultados retornados na } \\
\text { busca dentre outros dados. Você } \\
\text { identifica algum benefício em registrar } \\
\text { algum dos dados de consulta de busca } \\
\text { pesquisados em bases de dados de } \\
\text { patente na internet em algum formulário } \\
\text { ou documento? () vejo benefícios e } \\
\text { registro; } \\
\text { () vejo benefícios, mas não registro; () } \\
\text { Não vejo benefícios, mas registro; () } \\
\text { Não vejo benefícios e não registro; } \\
\text { Justifique e comente a opção escolhida } \\
\text { na resposta anterior. }\end{array}$ & $\begin{array}{l}\text { Criar a oportunidade de capturar } \\
\text { as indicações e justificativas do } \\
\text { respondente para não registrar e } \\
\text { se percebe algum benefício em } \\
\text { registrar, mesmo não } \\
\text { registrando. }\end{array}$ \\
\hline 28 & $\begin{array}{l}\text { Enunciado: Após você elaborar } \\
\text { uma consulta de busca e } \\
\text { submetê-la em uma base de }\end{array}$ & $\begin{array}{l}\text { Após você elaborar uma consulta de } \\
\text { busca e submetê-la em uma base de } \\
\text { dados de sua escolha, a tarefa de }\end{array}$ & $\begin{array}{l}\text { Permitir ao respondente } \\
\text { manifestar a alternância ou } \\
\text { ocorrência mútua dos }\end{array}$ \\
\hline
\end{tabular}




\begin{tabular}{|c|c|c|c|}
\hline & $\begin{array}{l}\text { dados de sua escolha, a tarefa } \\
\text { de registro dos dados de busca } \\
\text { ocorre antes ou após a } \\
\text { submissão? () Antes da } \\
\text { submissão; () Após a } \\
\text { submissão; } \\
\text { () Após a submissão, copiando } \\
\text { da página da base de dados para } \\
\text { o documento de registro. }\end{array}$ & $\begin{array}{l}\text { registro dos dados de busca ocorre } \\
\text { predominantemente antes ou após a } \\
\text { submissão? () Antes da submissão; () } \\
\text { Após a submissão; } \\
\text { () Após a submissão, copiando da } \\
\text { página da base de dados para o } \\
\text { documento de registro. } \\
\text { () Não há um comportamento } \\
\text { predominante, registro ora antes, ora } \\
\text { após a submissão. }\end{array}$ & $\begin{array}{l}\text { comportamentos apresentados } \\
\text { nas alternativas, também a } \\
\text { predominância de um tipo de } \\
\text { comportamento. }\end{array}$ \\
\hline 43 & $\begin{array}{l}\text { Enunciado: A realização de } \\
\text { tarefas inerentes à atividade de } \\
\text { busca como a análise de } \\
\text { resultados da busca e leitura de } \\
\text { documentos associadas com a } \\
\text { ação de memorização dos dados } \\
\text { de consulta até seu registro no } \\
\text { formulário promove uma } \\
\text { considerável demanda de } \\
\text { atenção, raciocínio e } \\
\text { memorização para o executor } \\
\text { da busca. }\end{array}$ & $\begin{array}{l}\text { Caso o executor da busca opte por } \\
\text { registrar os dados de consulta de busca } \\
\text { em algum momento após a submissão } \\
\text { dos mesmos nos campos de buscas do } \\
\text { site da base de dados de patente, a } \\
\text { realização de tarefas inerentes à } \\
\text { atividade de busca como a análise de } \\
\text { resultados da busca e leitura de } \\
\text { documentos associadas com a ação de } \\
\text { memorização dos dados de consulta até } \\
\text { seu registro no formulário promove } \\
\text { uma considerável demanda de atenção, } \\
\text { raciocínio e memorização para o } \\
\text { executor da busca. }\end{array}$ & \multirow{2}{*}{$\begin{array}{l}\text { Deixar claro que a situação } \\
\text { retratada no enunciado } \\
\text { contempla os casos em que o } \\
\text { executor da busca opte por } \\
\text { registrar os dados de consulta de } \\
\text { busca em algum momento após } \\
\text { a submissão dos mesmos nos } \\
\text { campos de buscas do site da base } \\
\text { de dados de patente, pois os que } \\
\text { registram de imediato não } \\
\text { precisam recorrer à } \\
\text { memorização por tempo } \\
\text { prolongado e não estão tão } \\
\text { susceptíveis ao esquecimento. }\end{array}$} \\
\hline 44 & $\begin{array}{l}\text { A carga de memória e } \\
\text { raciocínio advinda da realização } \\
\text { de tarefas inerentes à atividade } \\
\text { de busca como a análise de } \\
\text { resultados e leitura de } \\
\text { documentos juntamente com a } \\
\text { ação de memorização dos dados } \\
\text { de consulta de busca até seu } \\
\text { registro no formulário pode } \\
\text { provocar o esquecimento dos } \\
\text { dados e inviabilizar seu registro. }\end{array}$ & $\begin{array}{l}\text { Caso o executor da busca opte por } \\
\text { registrar os dados de consulta de busca } \\
\text { em algum momento após a submissão } \\
\text { dos mesmos nos campos de buscas do } \\
\text { site da base de dados de patente, a carga } \\
\text { de memória e raciocínio advinda da } \\
\text { realização de tarefas inerentes à } \\
\text { atividade de busca como a análise de } \\
\text { resultados e leitura de documentos } \\
\text { juntamente com a ação de memorização } \\
\text { dos dados de consulta de busca até seu } \\
\text { registro no formulário pode provocar o } \\
\text { esquecimento dos dados e inviabilizar } \\
\text { seu registro. }\end{array}$ & \\
\hline
\end{tabular}

QUADRO 2 - Comparação entre a redação das questões antes e após a intervenção. Fonte: Elaborado pelo autor

As questões 7 e 8 foram substituídas por uma única questão sem necessidade de validação. A condição de validação da questão 58 foi removida.

\section{CONCLUSÃO}

Na metodologia do pré-teste combinam-se os conceitos de Gil (1999) e Marconi e Lakatos (2010) num procedimento aprimorado, principiado nesta pesquisa, em que as manifestações expressas pelos respondentes no questionário foram retomadas e aprofundadas na entrevista para serem melhor compreendidas e exploradas, uma vez que tal exploração não seria possível no questionário devido à limitação no campo de resposta, que comportam poucas frases, e também limitação de tempo. A condução do entrevistador permitiu direcionar o respondente de modo que ele explique aspectos relevantes que ficaram eventualmente ausentes ou superficiais em sua manifestação do questionário, aprimorando-se o pré-teste. 
Dessa forma, os benefícios do novo procedimento permitiram ampliar a coleta de informações dos respondentes e também aprofundar a compreensão de tais informações, resultando em intervenções mais precisas na redação do questionário, aprimorando-o.

Obtém-se um questionário elaborado e testado para coleta de dados acerca do registro de dados busca por informação tecnológica que poderá ser aplicado em profissionais da área de inovação tecnológica, apto a obter informações para identificar se há a prática do registro de dados de consulta de busca, elucidar os motivos e usos do registro e a forma como é realizado.

O questionário serve de instrumento de coleta a ser reaproveitado e considerado em pesquisas dentro do mesmo tema, contribuindo para o desenvolvimento de ferramentas mais eficazes para busca de informações tecnológicas que fomentem os processos de inovação no Brasil.

\section{REFERÊNCIAS}

AAKER, D.; KUMAR, V.; DAY, G. Marketing research. Hoboken, Nova Jersey, EUA. John Wiley \& Sons, Inc. 1995.

BEUREN, I. M. Como elaborar pesquisas monográficos em contabilidade: teoria e prática. 2ed. São Paulo: Atlas, 2004.

CANHOTA, C. Qual a importância do estudo piloto? In: SILVA, E.E. (Org.). Investigação passo a passo: perguntas e respostas para investigação clínica. Lisboa: APMCG, 2008. p. 69-72.

FONSECA, C.B., CANHOTA, C., SILVA, E.E., SIMÕES, J., YAPHE, J., MAIA, M.C., RIBAS, M.J., MELO, M., NICOLA, P. J., BRAGA, R., RAMOS, V. Investigação passo a passo: perguntas e respostas para a investigação clínica. Lisboa,APMCG, 2008.

GIL, A. C. Métodos e técnicas de pesquisa social. São Paulo: Atlas, 1999.

GOODE, W.J.; HATT, P.K. Métodos em pesquisa social. 4a ed. São Paulo: Nacional, 1972.

JÜRGENS, J.; HANSEN, P.; WOMSER-HACKER, C. Going beyond CLEF-IP: The 'reality' for patent searchers? In proceedings of the third international conference of the clef initiative (CLEF 2012). Rome, Italy, Springer, pp. 30-35. 2012.

MACKEY, A.; GASS, S. Common data collection measures. Second language research: methodology and design. Mahwah: Lawrence Erlbaum, 2005. p. 43-99.

MANZATO, A.J.; SANTOS, A.B. A Elaboração de questionários na pesquisa quantitativa. Departamento de Ciência de Computação e Estatística-Universidade de Santa Catarina, 2012.

MANZINI, E.J. A Entrevista na pesquisa social. Didática, São Paulo, v. 26/27, p. 149-158, 1990/1991.

MANZINI, E.J. Considerações sobre a elaboração de roteiro para entrevista semiestruturada. In: MARQUEZINE, M.C.; ALMEIDA, M.A.; OMOTE, S. (Orgs.) Colóquios sobre pesquisa em Educação Especial. Londrina: eduel, 2003. p.11-25. 
MARCONI, M. A; LAKATOS, E. M. Fundamentos de metodologia científica. 7. ed. São Paulo: Atlas, 2010.

PARMAGNANI, R.M. O Glossário geral de ciência da informação. Brasília, Faculdade de Ciência da Informação (FCI) da Universidade de Brasília. 2004, Disponível em: http://www.cid.unb.br/publico/setores/100/123/sistema/m0039015.html. Acesso em: 25 Jun. 2020.

TANNEBAUM, W.; RAUBER, A. Learning keyword phrases from query logs of USPTO patent examiners for automatic query scope limitation in patent searching. World Patent Information. 2015.41. 10.1016/j.wpi.2015.02.005.

World Intellectual Property Organization. WIPO Guide to using patent information. 2015. https://www.wipo.int/edocs/pubdocs/en/wipo_pub_1434_3.pdf.. Acesso em: 10 Jun. 2019. 